\title{
AC 2010-1313: COMPUTER SIMULATION FOR MANUFACTURING PARTNERSHIPS
}

\section{Paul Nutter, Ohio Northern University}

Paul Nutter, CMfgE, CQE, CQA, is an Associate Professor in the Department of Technological

Studies at Ohio Northern University. He has been teaching manufacturing technology since 2000, and has 26 years experience in manufacturing and industrial engineering, primarily with

Rockwell Automotive. Paul is active in the Society of Manufacturing Engineers as faculty advisor for SME Student Chapter S186, is currently chair of the SME Automated manufacturing and Assembly Community, and has served as chair on the 2007 and 2008 SME Simulation Technical Group, on the 2006 SME Member Council, and the 2005 Student Relations

Subcommittee (chair). He has also participated on various committees for annual conferences and youth activities. 


\title{
Computer Simulation for Manufacturing Partnerships
}

\begin{abstract}
Computer simulations and advanced 3D CAD applications are being used extensively by major corporations to manage information and manufacturing operations across departmental, geographical and company boundaries. These technologies are important to communicate and consolidate vast amounts of information, especially for concurrent engineering efforts between work teams operating around the world. Schools, students, and companies benefit from opportunities to apply these to actual manufacturing problems in industrial environments.
\end{abstract}

The technology program at our university has historically included several classes in solid modeling and CAD software. For the past ten years computer simulations have been included to more effectively prepare students for use and application of these technologies. More recently numerous class projects with local manufacturing companies have been incorporated, and currently a three quarter sequence of courses is required for students in our Manufacturing Technology major. The initial course, Digital Manufacturing and Simulation (DMS) introduces students to these advanced design, analysis and data management applications. The two following classes focus on learning specific advanced simulation software, and the performance of actual projects in local industries, with formal presentation of the results to the company's management.

The following elements are included in this paper and presentation:

1. Description of our curriculum utilizing advanced 3D CAD and computer simulation software. Additional course topics include introduction to finite element analysis (FEA), collaborative Product Lifecycle Management (PLM), Virtual Reality (VR) modeling and animation, and 3D viewers for communication and production work instructions.

2. Results of manufacturing projects by student teams to create simulation models of actual industrial operations. Recent projects with Ford, General Dynamics, tier one suppliers to Honda and Jeep automotive assembly plants have analyzed robotics workcells, ergonomics, and discrete event materials and process flow operations.

3. Survey results from graduates and students who have completed this series of classes for their perspectives on the benefits and issues with this curriculum.

4. Documentation of successful student internships and job placements.

This paper and presentation explains how applications of computer simulation, advanced $\mathrm{CAD}$, and digital manufacturing have been incorporated in our technology curriculum, and provides examples of class projects completed at major industrial companies. These have resulted in excellent manufacturing partnerships and experiential learning opportunities, and have significantly benefited the students with internships and job placements. 


\section{Defining Computer Simulation for Manufacturing}

This paper deals specifically with computer simulations as applied to manufacturing operations, and is a significant component of Digital Manufacturing (DM). DM applications encompass a variety of computer-aided processes that are being embraced by companies of all sizes to remain competitive in the global market. Boeing is recognized for its design of the entire 777 airliner without using a single 2-D drawing - only 3D models were used. ${ }^{1}$ They have further increased their use of DM in their recently released 787 Dreamliner commercial jet, including the use of computer simulations.

One DM definition is "Digital manufacturing is the ability to describe every aspect of the designto-manufacture process digitally—using tools that include digital design, CAD, office documents, PLM systems, analysis software, simulation, CAM software and so on." 2

"Digital Manufacturing provides manufacturing and design engineers the benefit of enhanced visualization. In product design, powerful tools are frequently available for developing electronic product mockups, allowing engineers and non-engineers alike the ability to interact with a product before the design has been committed. Tools that allow $3 \mathrm{D}$ visualization replace sketches and drawings with something that comes much closer to the real world. By simulating the actual product that will be produced, countless mistakes are avoided and many improvements made. Time and expense have been reduced by reducing the number of physical prototypes that must be created in order to validate a product design in the physical world." 3

Computer simulation is one of the principle applications within the DM realm. The Society of Manufacturing Engineers (SME) has created a technical group to provide reference information and networking opportunities within this field. This group has designated four areas of computer simulation related to manufacturing operations: ${ }^{4}$

1. Virtual product design

2. Physical prototype validation

3. Production/operations analysis

4. Enterprise analysis

The principle applications used in our simulation curriculum fall within the production/operations domain.

\section{Simulation Significance and Opportunities}

Modern manufacturing operations are increasingly dependent upon the synergies of employees, vendors and customers to achieve excellent performance. Creation of a common vision for project proposals and process improvements are essential for effective and efficient project and program implementations, and to stimulate best ideas and practices. The ability to communicate and capture ideas and proposals that can be shared across a broad cross section of personnel are integral components of concurrent engineering, cross-functional teams, lean manufacturing, and self-directed work teams. These are the mechanisms that have permitted Japanese and Asian companies to dominate in many industries, and which are being embraced by the most successful American manufacturers. 
The original math based simulation applications of several years ago were primarily the domain of industrial and systems engineers for analysis and interpretation. The high visual nature of the newer object based simulations lends themselves particularly well to current management trends utilizing cross-functional teams and concurrent engineering. As illustrated in Figure 1, the use of the animation functionalities provides workers, technicians and management better understanding and conceptualization of new layouts and processes before they are built, permitting improved brainstorming and idea generation.

$\begin{array}{ll}\begin{array}{l}\text { Math based simulations } \\ \text { (Objective, Analytical) }\end{array} & \begin{array}{l}\text { Industrial/Systems Engineers } \\ \text { Mechanical Engineers } \\ \text { Manufacturing Engineers } \\ \text { Management } \\ \begin{array}{l}\text { Object based simulations } \\ \text { (Visual, Intuitive) }\end{array}\end{array} \quad \begin{array}{l}\text { Technicians } \\ \text { Workers }\end{array}\end{array}$

Figure 1: Simulation Spectrum of Comprehension.

At our school additional simulation applications are planned or under evaluation for incorporation into the technology curriculum. These include Delmia's V5 DPM Powertrain, Process Engineer, and Workload Linebalance, along with other applications in demand by industry. Planning is also in progress for integration of the Delmia simulation applications into other University courses, including PLC's and Industrial Robotics, CAD/CAM and Automation Systems, and Advanced Robotics and Automation.

\section{State of the Art of Digital Manufacturing}

A study by the National Research Council identified "synthesis, modeling, and simulation for all manufacturing operations" as one of the top ten technology areas for meeting the challenges of manufacturing in the year $2020^{5}$. The report also identifies significant opportunities in workforce education and training: "Educational and training methods that would enable workers to assimilate knowledge to improve their effectiveness are priority technologies.

"Research opportunities include the development of tools that are not language or culturally dependent; technologies that can capitalize on advances in the cognitive sciences; interactive techniques, including simulation and virtual reality; and learning modules that can be adapted and tailored to meet individualized educational needs." ibid. (Italics added)

Many of the opportunities relate to new visualization and documentation applications using 3D graphics and convenient annotations. New products by Adobe Systems (Adobe Acrobat 3D), Dassault Systemes (3DVIA), and others, along with new developments in virtual reality technologies, will permit communications and collaborations that are not language or geometry based, but visually convey information in forms that humans easily understand. These are already being integrated into Product Lifecycle Management (PLM) systems in some companies.

"Digital manufacturing solutions are part of collaborative PLM systems and make up the manufacturing element of PLM, including integrated solutions supporting manufacturing process design, tool design, and powerful 3-D visualization simulation tools. The integration of digital manufacturing into PLM solutions is providing a critical link between design and manufacturing engineering, according to market researcher ARC Advisory Group (Dedham, MA), enabling the 
collaborative environment that is essential to successfully implementing concurrent engineering practices." 6

\section{Curriculum Background at Our University}

A grant from the Society of Manufacturing Engineers in 1997 permitted the initial offering of virtual simulation (VS) as a senior capstone project for technology majors. By the summer of 1999, simulation internships had placed 12 of 17 students after running full-scale simulation classes ${ }^{7}$. Internship placements included NASA-Johnson Space Center, a Navistar truck plant, Deneb Robotics, DaimlerChrysler, and General Motors. By 2000 graduates with these skills received the following successful job placements: Applied Manufacturing Technologies (Systems Engineer); Argus \& Associates (Simulation Engineer); Delphi Corp. (Simulation Engineer); Delmia (7 Interns); Detroit Central Tool (Robotics Simulator); General Motors (Simulation Engineer); and HRU Corp. (Project/Simulation Engineer).

\section{Computer Simulation Curriculum Overview}

Based on successful job placements, and demand by students, computer simulation is now a principle component of the Manufacturing Technology major in the Department of Technological Studies, and is offered as three distinct courses. These courses are for junior and senior level students, and have a programming course pre-requisite. All students in this major have had previous CAD/CAM coursework, which provides them with experience using similar applications. The course materials use a combination of the tutorials, exercises, and reality-based individual and team projects.

Initial problems in the program implementation included the high initial cost of the lab facilities, and the annual expenses for software (initially $\$ 25,000 /$ year). A grant from the Society of Manufacturing Engineers assisted in the initial investments and course development. The university has consistently supported this curriculum as a distinctive and appropriate component that supports the mission of the institution.

The Technological Studies Department is currently utilizing the manufacturing simulation software offered by Dassault Systemes and their subsidiary Delmia Corp. of Auburn Hills, MI. The products used during 2009-2010 include CATIA V5 for advanced CAD design, and for simulations DPM Envision Assembly (assembly/disassembly sequencing), Human Modeling (ergonomics analysis), Robotics, and QUEST (discrete event material and process flow analysis). An educational partnership provides major software discounts, support, and training materials at costs that are practical for our program. For example, the educational pricing for ten seats of the simulation software licensing for the 2006-2007 year was approximately $\$ 16,000$. Two year pricing options reduced the 2007-2008 cost to just over $\$ 5,000$, bringing our average cost per year to approximately $\$ 10,500$. This includes nearly their entire suite of simulation software, and has an additional seat for a laptop computer. The quoted annual "commercial value" for all of these is well over $\$ 4,000,000$. New pricing is being established as we end our initial two-year contract.

An advantage of utilizing the Dassault suite of products is the common interfaces between their various applications. The applications work together seamlessly, with the ability to switch 
between various "workbenches" for each application while working on the same model. The high visual and graphical results have also proven effective in stimulating student interest in the Technological Studies program, countering some public negativism for industrial/manufacturing occupations.

An additional incentive has been the extensive use of this specific simulation software by major companies in our geographical region (Honda, Chrysler, General Dynamics, and Toyota), and significant opportunities for internships, co-ops and jobs using this software at automotive OEMs, major defense industries, and their tier one suppliers. Also the incorporation of such advanced computer simulation applications into an undergraduate program has served to differentiate ours from other industrial technology programs.

The lab facilities for these classes include 14 high-end computer workstations equipped with dual monitors. The students learn the various simulation applications through tutorials, and then create independent individual or team projects to demonstrate and develop basic competencies. During the winter and spring quarters student teams are then formed to complete industrial company projects. The teams visit local manufacturing operations to observe their processes, create simulations of the projects, and present the results at the company facility upon completion, including digital videos of the simulations and PowerPoint presentations. At the beginning of these quarters, new projects are identified at local companies that apply the specific software applications for the quarter. Student teams are formed based on their expressed interest to work with a specific company or convenience for some to work together. Efforts are made to change team members each quarter. At the completion of these three courses each student creates and presents a portfolio DVD summarizing all of their work during this sequence.

This curriculum has benefited our program in many ways:

Incorporation of several industrial technology applications into these classes:

1. 3-D solid modeling and data translation

2. Robotics construction, kinematics, robot programming

3. Ergonomics analysis

4. Assembly sequencing

5. Production layout \& material flow optimization

6. Formal multi-media presentations to industrial professionals

7. Creation of personal portfolio and CD

General benefits and opportunities for our students and our program:

1. Practical application of an advanced technology

2. Generates student enthusiasm for manufacturing

3. Excellent project coordination tool for concurrent engineering

4. Teamwork activities

5. Project planning

6. Problem solving

7. Industrial exposure

8. Co-op/Internship opportunities

9. Job Placement contacts

10. CAD/CAM systems experience 
11. Application of other industrial technology applications and curricula

\section{Specific Computer Simulation and Digital Manufacturing Coursework}

The sequence for these courses may be summarized as follows:

- Fall Quarter

- Digital Manufacturing Design and Applications (CATIA CAD)

- Winter Quarter

- DELMIA V5 Simulation (Ergonomics, robotics, and assembly analysis)

- Industrial Team Project

- $\quad$ Spring Quarter

- DELMIA D5 and Process Engineer (Discrete event process simulation)

- Industrial Team Project

TECH 321 - Digital Manufacturing Design and Applications: This course covers the use of advanced 3D CAD solid/parametric modeling software in the design of parts and products. It includes an overview of digital manufacturing systems, computer simulation applications, product lifecycle management, and use of resource planning/database systems. Training materials included the "CATIA Intro to Modeling" manual (by Ascent/RAND), online Dassault tutorials and training materials, professional webinars by Dassault, RAND, professional organizations and Dassault resellers, reference materials from the Society of manufacturing Engineers (SME) Simulation Technical Group, and IMMERSIVE Engineering's internet-based digital-manufacturing learning management system. For a term project teams of students disassemble and model a mechanical devise and present the results in a PowerPoint presentation.

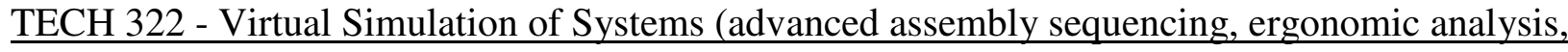
and robotics ): Students learn computer simulation applications using tutorials and training materials provided by Delmia. They then create individual simulation projects demonstrating their proficiencies and present the results to the class.

Approximately midway through the ten-week quarter the students are split into teams of three to five persons for assignment to a company project. Based on individual preferences or company restrictions (e.g.; US citizenship) the project is designated and arrangements made for a plant visit. Typically, a 1-2 hour meeting with the company includes an explanation of their business, a general description of the operation(s) to be simulated, and a tour of the plant and specific operation(s). Data is provided then and upon request, including pictures and videos if available. The team observes the plant operations, discuss the issues and company expectations, gather relevant data and information, and begin creation of the simulation. Additional plant visits and company communications are the responsibility of the students. A Gantt chart from Microsoft Project is submitted weekly, and the professor monitors project progress. During the tenth week of the quarter, the team presents the results of the simulation and analysis to representatives of the company, along with basic suggestions; typically lasting thirty minutes to an hour. A final comprehensive portfolio of each student's work for the quarter, including video files of their projects, is made in a PowerPoint presentation to the class and submitted on a DVD.

TECH 423 - Virtual Simulation-Production \& Management (material and process flow analysis): Quest tutorials from Delmia are used for the student training, with specific exercises at the end of each chapter that are submitted electronically for grading. Each student creates and presents a 
unique, complex manufacturing system of their own design or personal experience utilizing most of the standard components of the software. Following this the classes are again divided into teams who go into manufacturing companies and create a simulation of a specific operation or process. Team presentations and suggestions are presented to company officials.

At the end of the full sequence of courses, each student formally presents to the class a final comprehensive portfolio of their VS projects. These portfolios are intended to be suitable for presentation to a perspective employer, and are graded as their final exam.

\section{Computer Simulation Project Examples and Descriptions}

Following are descriptions of sample simulation projects completed during the past academic year.

Fall Quarter: Digital Manufacturing Design and Applications:

Upon completion of CATIA training the students were assigned to complete a team project from an existing product that included "waku-waku," which results from a presentation at the 2007 DELMIA User Conference where a Honda manager emphasized this as a core component of the Honda philosophy and products. His interpretation of "waku-waku" is that their product should be "sexy." Figure 2. This proved to be an assignment that generated high student motivation, work effort and satisfaction.

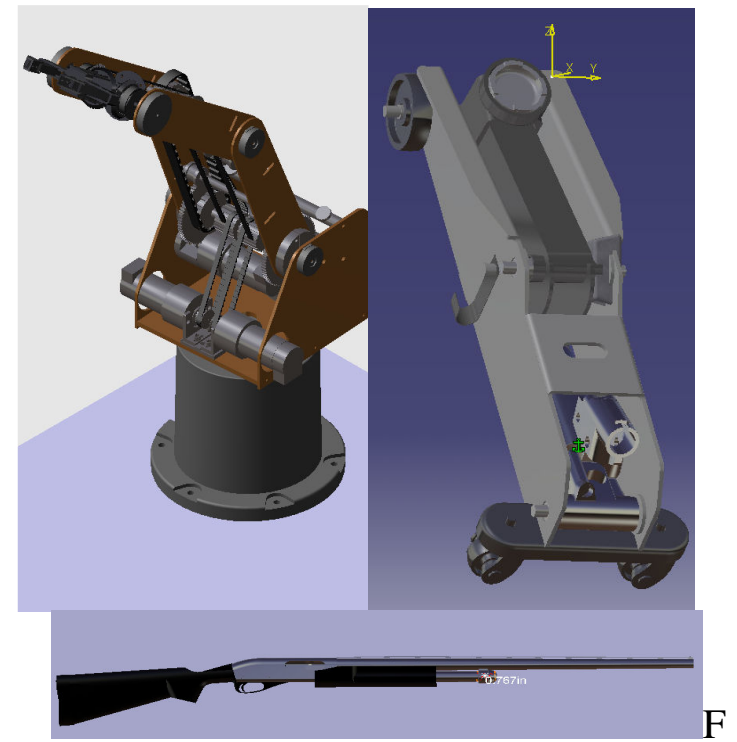

ig. 2: 2008-09 CATIA Projects:

Scorbot Robot, Hydraulic Jack, Shotgun

Winter Quarter

2008-2009:

Robotics Workcell proposals

Figures 3 shows three workcell proposals developed by students to incorporate robotics and consolidate operations based on simulation analysis.

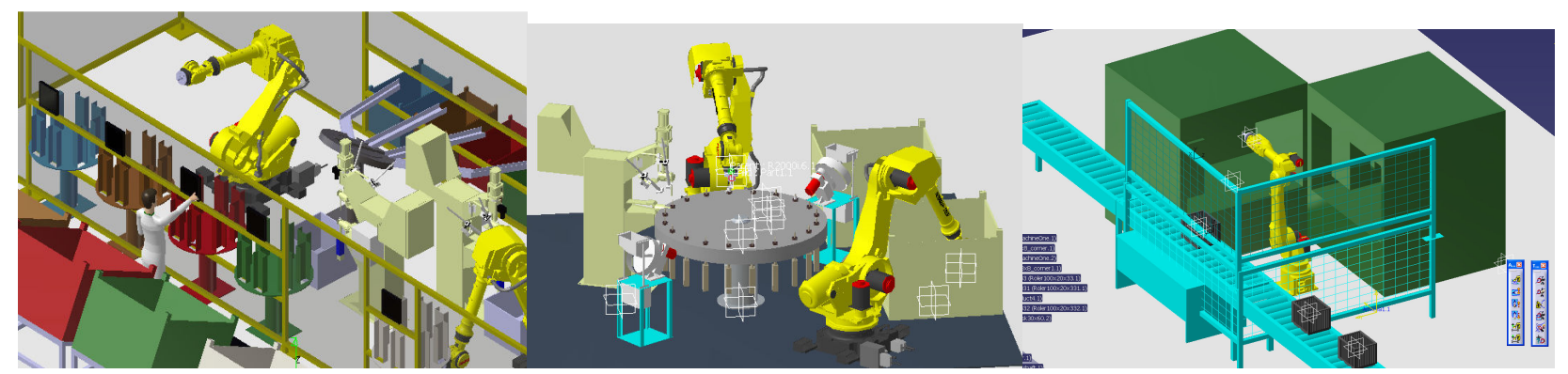

Figure 3: Robotics Analysis of three Automotive Workcells 
Human Solutions:

An ergonomic analysis was completed for operators at robotic workcells at two tier one suppliers to Honda automotive. This study identified opportunities for fatigue and repetitive motion stress reduction. See Figure 4.

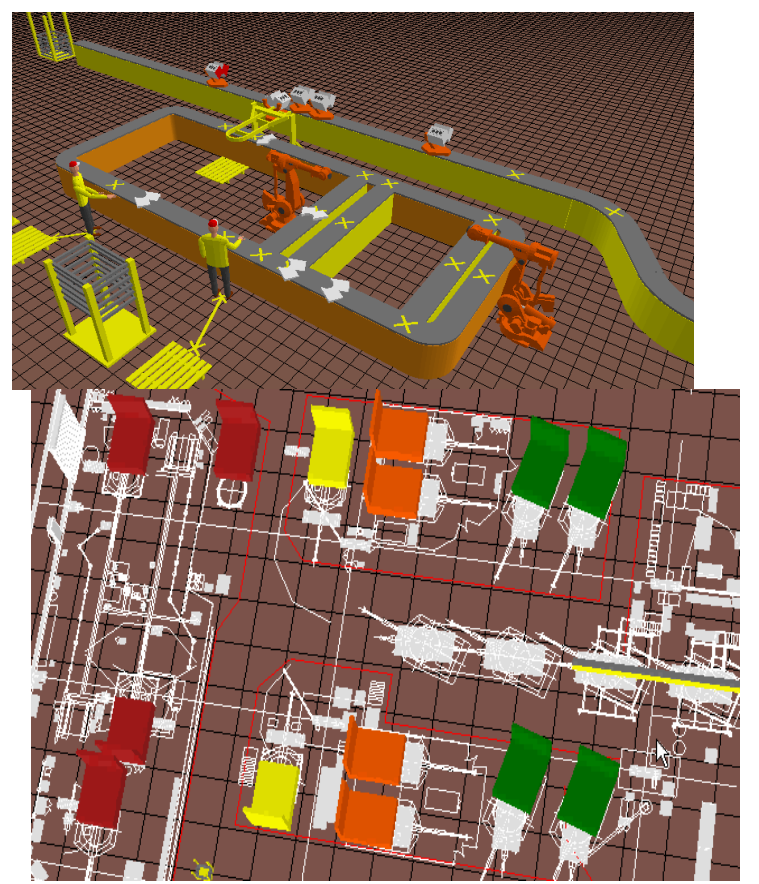

Figure 5: Discrete Event Material Flow Analysis

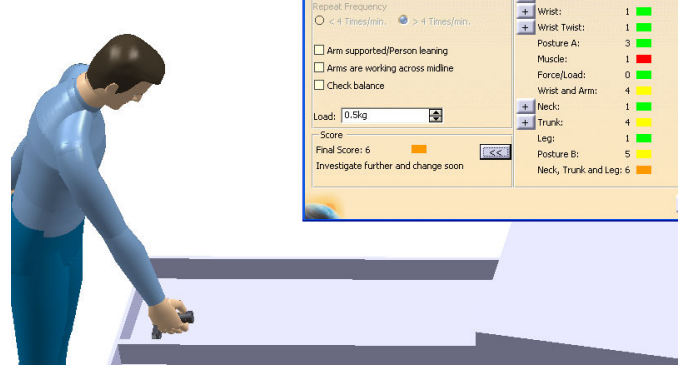

Figure 4: Ergonomic Analysis of two Workcells

Spring Quarter 2008-09:

QUEST Discrete event Material and Process Flow Analysis:

Simulations were completed for three workcells. One at a Ford engine plant included process logic for assembly of components. A proposal for a General Dynamics plant evaluated options to improve throughput of a military product through bottleneck operations. A third simulation at a tier one Honda supplier provided recommendations for a major reorganization of production equipment for transmission components.

See Figure 5.

\section{Company Collaborations}

The issue of getting company involvement required some persistence. The cooperation was gained largely by offering the opportunity for company representatives and management to influence students to pursue manufacturing jobs (appealing to their personal interests, and "parenting" emotions), plus opportunities for employees to demonstrate community service. Now there is very good acceptance and support. The essential component in achieving successful company projects has been the establishment of a working relationship with individuals in the company who had the authority, interest, and willingness to get involved. All companies have been supportive and cooperative once the relationship was established, although it sometimes took patience, perseverance and repeated communications to achieve this cooperation. All contacts were very busy, but were receptive to the idea of providing the opportunity for students to gain first hand real world experience in dealing with manufacturing issues. The expectations of both parties and the deliverables are identified in the initial meeting between the students and the company representatives. When the projects were underway, and they found our needs were not very demanding, the willingness to provide support and even encouragement grew. The companies have expressed high satisfaction with the results of the students' work, with offers to provide future projects. They have also expressed a willingness to pursue opportunities for financial grants and other partnership activities. 


\section{Student Issues, Successes and Satisfaction}

Students have usually struggled with management these real-life projects, and with division of responsibilities and on-time project completion issues, but have usually come through with results well received by companies. The computer simulation curriculum continues to provide graduates with excellent internship and job opportunities.

A salary survey of placements for student graduates from 2003-2005 substantiates the benefits of this program. The average initial compensation reported for all graduates of the technology program for the three years is $\$ 39,689$. The average during the same period for graduates that took the advanced manufacturing option or the virtual simulation minor and took jobs in a related field is $\$ 45,214$, which is $14 \%$ higher than the overall average.

Students graduating from our program have had excellent six job placements as follows: $96 \%$ in $2007,86 \%$ in 2008 , and $95 \%$ in $2009 .{ }^{8}$ Recent placements using these technologies include NASA, General Dynamics, Delmia, TechniGraphics Engineering, plus several tier 1 and tier 2 suppliers and system integration/simulation development companies.

Following are results of a survey taken winter quarter of 2009-10 of recent graduates at the companies listed above who have been working in this field.

1. Have you seen significant benefits at your companies through the use of computer simulations? If so, can you provide an indication or quantification of these benefits?

$>$ Yes, we have seen significant benefits using simulation software. We are able to simulate welding fixture and robot weld gun interaction when these fixtures are designed in 3D. This simulation is done as the fixtures are being designed allowing us to catch interferences before anything is even built including the weld guns and / or any end-of-arm tooling. This saves us both time and money because any delay while teaching a weld line can result in it not being online in time for mass production. Another benefit is the off-line programming capability of our software. We are able to simulate entire weld assembly lines before they are built and program all of the robots including interference zones and Input/Output communication. Once these programs are downloaded to the actual robots on the floor only minor reteaching is needed to make them accurate. This reduces the time it takes to get the robots operational and ready to run production. Although it may take either the same time or longer to program the robots off line, the time it takes online is reduced so this is still a benefit. It has taken KTH a few years to get this software to work correctly but now that it does the time savings should be quite substantial.

$>$ Our division of the company is based solely on 3D data and simulation applications, so I have most definitely seen the benefits of having such skills. Also we serve as a "bail out" for other companies who may hire us because their employees do not have sufficient experience with CAD and simulation, or they simply do not have the time to do massive data conversion of legacy data. 
2. Which specific application of manufacturing simulation are showing the greatest benefits or opportunities?

$>$ Robotic Simulation (Delmia V5 Robotics w/ the OLP Suite)

$>$ It seems the most profitable and common application in our field at the moment would be data conversion ( $2 \mathrm{~d}$ to $3 \mathrm{~d}$, or $3 \mathrm{~d}$ to $2 \mathrm{~d}$, or $3 \mathrm{~d}$ to $3 \mathrm{~d}$ in different software platforms). Another emerging application would be the use of 3D simulations for work instructions. This can show the exact way something is assembled or disassembled visually in $3 \mathrm{~d}$ allowing for better communication all along the PLM stream.

3. Are your companies making significant investments of financial and human resources in these technologies?

$>$ Traditional simulation has been a small operation at KTH. However we have recently migrated to the V5 platform from D5 and purchased 2 licenses. Doing this took a significant financial investment. Currently only 1 associate is working full time with the simulation software and 3 other associates are trained on it. KTH's goal is to train more associates and purchase additional licenses once we are able to get a better understanding of how everything works.

$>\mathrm{We}$ are currently expanding in the hopes that our workload will continue to increase. It seems that many manufacturing companies are currently hesitant to expand in the area of simulation due to tighter budgets. However, when something arises where those same companies need some work done in 3D, we are more than happy to step in and do the work for them!

4. How much did this simulation curriculum benefit you personally in your career development?

$>$ Personally my training at Ohio Northern benefited me very much. Even though I trained on Delmia's D5 platform IGRIP the same logical thinking and general user interface helped me when I continued using it after graduation and even when I migrated to Delmia V5. Even when I went to Delmia's company training I was able to rely on my past education to learn faster than anyone else in the class.

$>$ To be quite honest, between the technical skills gained and the exposure to real world business through the company projects, the simulation curriculum was the most critical factor in me gaining and maintaining employment. You could say I am now a professional Virt Simmer! (our curriculum has been called virtual simulation)

5. Other comments:

$>$ Simulation is great for companies like KTH. However, it takes some time for other associates and management to fully appreciate it. A few bad results can really hinder forward progress. I like to set really difficult targets for my OLP accuracy like +/$10 \mathrm{~mm}$ when everyone says that there is no way you will achieve it. The look on their faces when I achieve my target is great. 
All I can say in terms of the Sim (simulation) program at ONU is that I have personally heard from some higher up folks in the company that they don't know why they look anywhere else for their new employees! The combination of manufacturing knowledge and CATIA skills are very desirable in a field like TechniGraphics is in. In addition, the exposure to different types of projects and assignments in college made me a more flexible worker with a better ability to change my mind set for each job.

\section{Class Evaluation Comments:}

Students have been attracted by, and demonstrated enthusiasm for, working with the visual computer-oriented nature of simulations, but have been impatient working through the details and complexity of the applications. A trainer of the IGRIP product at Delmia made the comment that it takes two years using the products full time in industrial applications to achieve $90 \%$ proficiency; this statement has been used to assure the students that they should not get frustrated, and that they should plan on extended usage to achieve high competency levels. Although basic proficiencies are desired, the more important objective is an understanding of how these tools are used. Further training is expected at the employer in the specific applications the company utilizes. Manufacturing simulation programs are being used at other universities, including several using Delmia in limited applications or graduate work, but no others are believed to have the number of courses or with the number of industrial projects achieved as at our school.

\section{Summary}

Manufacturing companies are pushing the envelope to gain competitive advantages through rapid development of new products, processes and production systems in lean environments that emphasize continuous improvement. Companies are embracing digital manufacturing, product lifecycle management and simulation analysis as tools to achieve their goals. Boeing, General Motors, the United States military, and others are mandating that simulations of major projects be completed prior to implementation. Graduates of engineering and technology programs with an understanding and ability to apply these tools will find many opportunities as our economy continues to grow.

During the 2008-2009 school year requests for graduates, co-ops and internships with simulation experience significantly exceeded our supply of students choosing to follow this career path. The virtual simulation program is a distinctive component of the Department of Technological Studies, and provides excellent opportunities for student field experiences and applications of advanced computer technologies. The curriculum provides the opportunity for real-world projects, internships and jobs for our students, and is providing modern industrial companies with effective management and manufacturing engineering professionals. The local industrial companies have been very receptive and supportive of the partnerships that improve the quality of the students' education and better prepare them for future opportunities in manufacturing. 


\section{Bibliography}

1. Society of Manufacturing Engineers, Manufacturing Engineering Magazine, "PLM in Aerospace," March 2007, pp. 127-139

2. Rachael Dalton-Taggart, Tooling \& Production Magazine, "The Move to Digital Manufacturing." Online at http://www.manufacturingcenter.com/tooling/archives/0405/0405move to digital.asp

3. Jim Brown, Tech-Clarity, Inc., "Digital Manufacturing-The PLM Approach to Better Manufacturing Processes" 2004.

4. Society of Manufacturing Engineers, Simulation Technical Group website. 2008, http://www.sme.org/cgi-bin/communities.pl?/communities/techgroups/simulation/simulation.htm\&\&\&SME\&

5. National Research Council. Visionary Manufacturing Challenges for 2020, Washington DC: National Academy Press. 1998.

6. Society of Manufacturing Engineers, Manufacturing Engineering Magazine, "Enter the Virtual World" October 2007, pp. 67-82

7. Shearrow, C., Successful Simulation Internships and Curriculum Deployment (unspecified) University, Unpublished PowerPoint presentation. 1999.

8. Placement Assessment Report for the Graduating Class of 2009, ONU office of Career Services, January, 2010 